Research Article

\title{
Diagnosis and Fault-Tolerant Control of Six-Phase Wind Turbine under Multiple Open-Switch Faults
}

\author{
Rouhollah Bolbolnia $\mathbb{D}^{1},{ }^{1}$ Karim Abbaszadeh $\mathbb{D D}^{1}{ }^{1}$ and Mojtaba Nasiri $\mathbb{D}^{2}$ \\ ${ }^{1}$ Department of Electrical and Computer Engineering, K. N. Toosi University of Technology, Tehran, Iran \\ ${ }^{2}$ Solar Energy Applications Group, School of Engineering, Trinity College Dublin, Dublin 2, Ireland \\ Correspondence should be addressed to Rouhollah Bolbolnia; r.bolbolnia@email.kntu.ac.ir
}

Received 30 March 2021; Revised 18 July 2021; Accepted 20 September 2021; Published 7 October 2021

Academic Editor: Adrian Neagu

Copyright (c) 2021 Rouhollah Bolbolnia et al. This is an open access article distributed under the Creative Commons Attribution License, which permits unrestricted use, distribution, and reproduction in any medium, provided the original work is properly cited.

\begin{abstract}
A new open-switch fault diagnosis method is proposed in this paper for the six-phase AC-DC converter based on the difference between the phase current and the corresponding reference using an adaptive threshold. The single and multiple open-switch faults are detected without any additional equipment and complicated calculations since the proposed fault detection method is integrated with the hysteresis controller. The proposed fault-tolerant technique reduces the value of overcurrent and total harmonic distortion on the side phases of the faulty one, by changing the switching signal of one switch in its opposite phase in some regions. This technique is performed without adding any legs, switches, or triode for alternating currents to the circuit. Finally, the proposed fault-tolerant technique is evaluated by MATLAB simulation and the results show its effectiveness.
\end{abstract}

\section{Introduction}

Recently, due to the rapid growth of wind energy and its significant effect on the power grid, the reliability and availability of wind energy systems have become very important [1]. A wind turbine with a permanent magnet synchronous generator (PMSG) has the advantages of high density and efficiency and increased reliability due to the absence of gearboxes [2]. These benefits alleviate the investment concerns in a PMSG wind turbine [3]. On the other hand, using multiphase generators in wind turbine systems provides more advantages such as reducing the amplitude of pulsating torque and increasing its frequency, decreasing the stator copper loss, and lowering the current per-phase for the same rated voltage. Moreover, multiphase generators improve reliability and increase the degree of freedom [4]. Therefore, a six-phase PMSG is one of the best choices for a wind turbine system. A wind turbine equipped with a sixphase PMSG requires a full-scale converter to inject the desired power into the grid. According to recent studies [5], the most vulnerable components of a wind turbine system are its power electronics devices and the most faults are originated from power switches, resulting in $25 \%$ of failures.
Another survey [6] shows that power electronic converters are responsible for more than $22 \%$ of the overall downtimes in wind farms, which is the longest one of all. Generally, power switch faults are categorized into two types of shortcircuit and open-switch faults. Unlike the short-circuit fault, the open-switch fault does not cause the system to immediately shut down and can remain undetected for a while [7]. However, it can disrupt the performance and reliability of the system, lead to secondary faults in the converter, eventually resulting in complete shutdown of the system $[8,9]$. In order to improve the reliability and availability levels and reduce maintenance costs, both diagnostic and fault-tolerant methods with acceptable performance are needed until the situation is revised $[10,11]$.

In general, diagnostic methods can be categorized into the following three groups: model-based, knowledge-based, and signal-based. By employing an observer in [12, 13], a model-based fault diagnostic approach was implemented. However, the model-based methods require accurate information of the system model and are extremely sensitive to the system parameter variations [7]. In [14], a knowledgebased fuzzy fault diagnosis method for the voltage source inverters was proposed. Nevertheless, the knowledge-based 
methods need the historic data of the system and require long training and a huge computational effort. The signalbased methods are realized by examining the characteristics of voltage and current signals. A single open-switch fault diagnostic method based on a comparison between the measured voltage and the reference value was presented for a doubly fed wind power system in $[1,15]$. Voltage-based diagnostic methods increase the system cost, complexity, and the potential of fault on additional equipment like voltage sensors [16]. Current-based methods are widely used for single and multiple open-switch fault detection since they require neither accurate model of the system, complicated calculations, nor additional equipment [10]. The current Park's vector and the average current Park's vector methods were introduced in $[17,18]$, whereas the openswitch fault was determined by using the phase angle. A comparison between the phase angle slope of the current Park's vector and a constant threshold was suggested in $[19,20]$. The fault diagnosis indicator is normalized to be independent of load changes. In $[21,22]$, the fundamental component and the average absolute value of the current were considered as normalizing variables. In [23], the instantaneous value of the current was proposed as a normalizing variable. The constant thresholds usually need to be adjusted according to the operating point variation or reference values, which can decrease the reliability of fault diagnosis techniques [24]. In [25], the adaptive threshold is used instead of the constant threshold to increase robustness. These techniques detect open-switch faults in conventional three-phase converters with six switches but they have not been analyzed for multiphase systems, yet.

Various structures were proposed for open-switch faulttolerant. In [26, 27], an additional leg was connected to the converter phases by triode for alternating currents (TRIACs), while in [28], this additional leg was connected to the neutral point of the machine. Besides, in [29] and [30], the additional switches were removed, and only by TRIACs, the capacitors midpoint of DC-link was connected to the converter phases or the neutral point of the machine or grid transformer [31, 32]. Also in [33], both sides (grid/machine) of the back-to-back converter were connected to each other through TRIACs. Additional equipment such as switches and TRIACs increases the cost and complexity of the system. In some researches $[8,34,35]$, the fault-tolerant method was implemented by revising the PWM switching pattern, which prevents the system cost to increase. Also, these methods have not been evaluated for multiphase systems.

This paper presents a fault diagnosis technique for single and multiple open-switch faults in a six-phase AC-DC converter as part of a multiphase wind turbine system. The novelties of this paper can be classified as follows:

(1) The proposed fault detection method only requires the information given by current sensors and their reference signals

(2) These currents and their reference information are already provided by the main control system and there is no need for additional sensors or complicated calculations
(3) After fault detection, without any additional equipment, the fault-tolerant method is performed by revising the switching pattern of the opposite phase of the faulty ones in some regions

(4) The proposed fault-tolerant method reduces the overcurrent and the total harmonic distortion (THD) of current in healthy phases

This paper is arranged as follows: The six-phase AC-DC converter model used in the wind turbine is presented in Section 2. Fault detection technique and fault-tolerant method for single and multiple open-switch faults are introduced in Section 3 and Section 4, respectively. In Section 5 , the performance of the proposed fault-tolerant method is evaluated by utilizing simulation results. Finally, in Section 6 , conclusions are presented.

\section{Description of the Six-Phase Wind Turbine with the AC-DC Converter Model}

A wind turbine based on a six-phase PMSG is connected to the grid via a full-scale back-to-back converter. According to Figure 1, this converter consists of two parts, machine side converter (MSC) and grid side converter (GSC), which are connected to each other through the DC-link capacitor. As the six-phase MSC has 12 switches (twice the three-phase system), open-switch fault diagnosis and fault-tolerant are very important in this converter. Many fault detection and fault-tolerant methods have been developed for DC-AC inverter; however, there are a few types of research for ACDC converter [8]. This paper uses a six-phase AC-DC converter without grid connection and considers a local load as a consumer according to Figure 2.

Figure 3 demonstrates a hysteresis current controller in a six-phase AC-DC converter to maintain the DC-link voltage at the required value. The main advantage of the hysteresis controller is its simplicity, fast response, and load-independent performance [36]. A proportional integral (PI) controller is used to regulate the DC-link voltage and its reference value [37]. The output of the DC-link voltage controller is considered as the reference current $I_{r e f}$ in the hysteresis controller. The reference current waveform is obtained from the voltage waveform of the same phase. Switching signals for each phase are generated by comparing the phase current with its reference value and considering the hysteresis band. If the difference between the reference current and the actual current of the same phase is greater than the hysteresis band, the upper switch of that phase will turn on. Otherwise, the bottom switch of that phase will turn on. The differential equation of the six-phase AC-DC converter is given by

$$
u_{s n}(t)=L \frac{\mathrm{d} i_{s n}}{\mathrm{~d} t}+R i_{s n}(t)+u_{\bmod -n}(t) \quad n=a, b, c, x, y, z,
$$

where $u_{s}$ is the voltage source and $u_{\text {mod }}$ is the converter voltage. $L$ is the filter's inductance, and $R$ is the resistance. The six-phase converter equations are transferred to the $d q$ rotation frame by considering the $T_{62}$ matrix. 


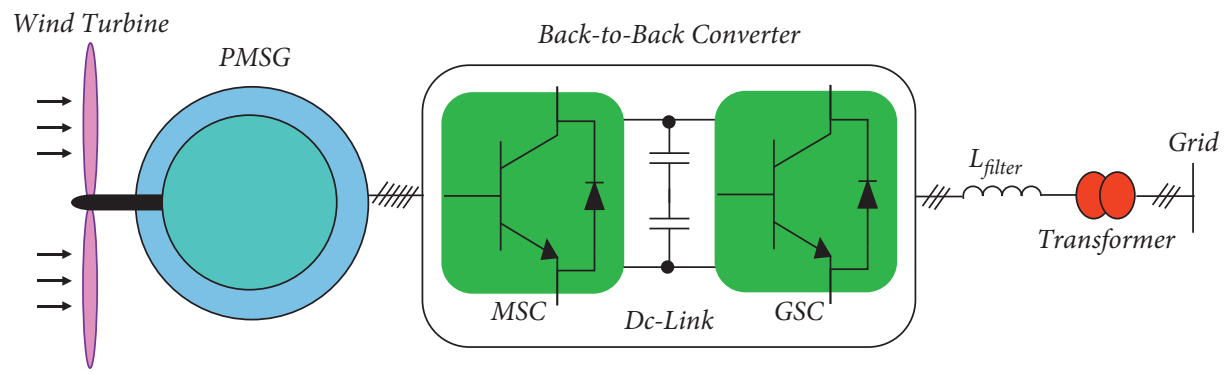

Figure 1: The six-phase PMSG-based wind turbine system configuration.

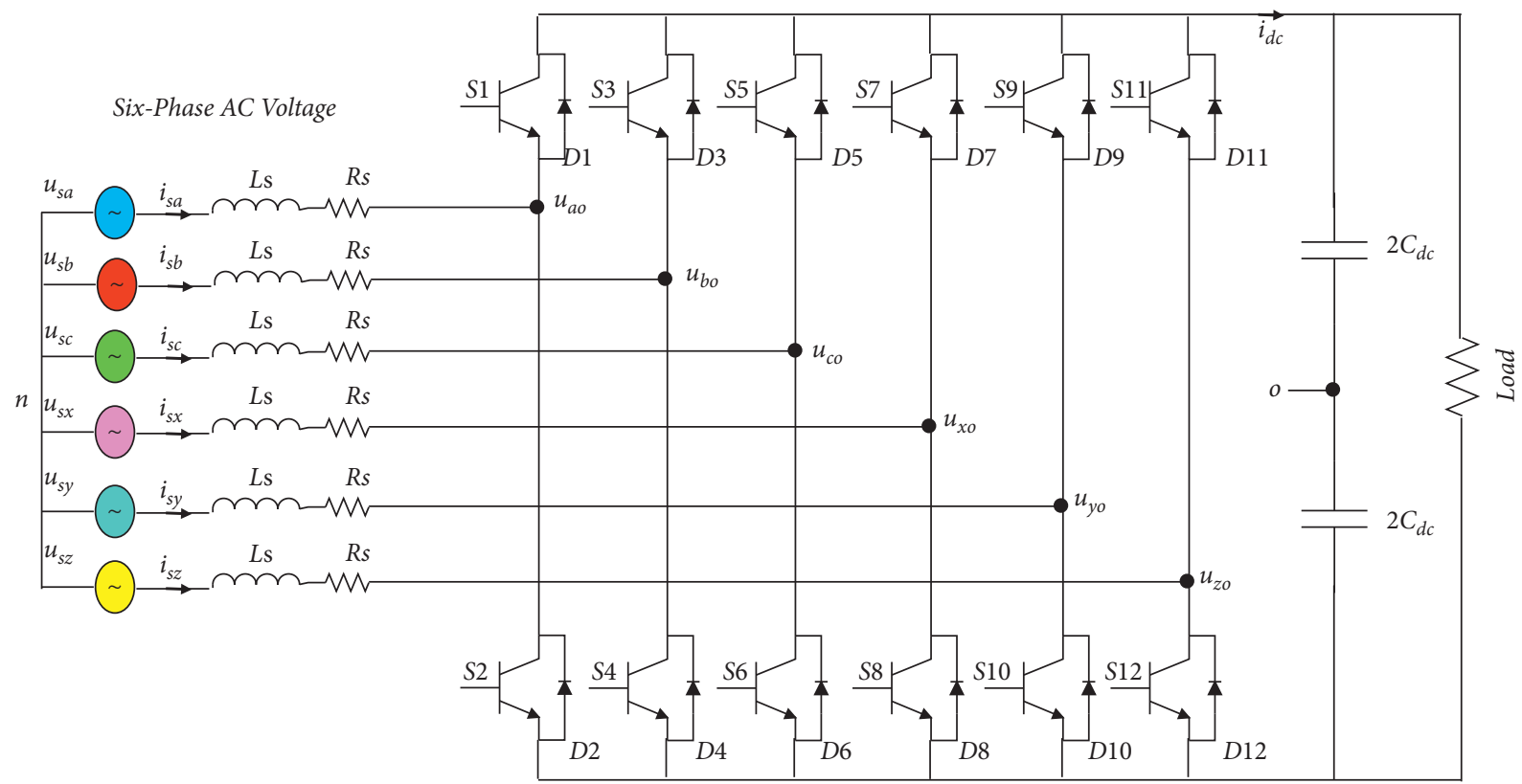

FIgURe 2: Six-phase AC-DC PWM converter.

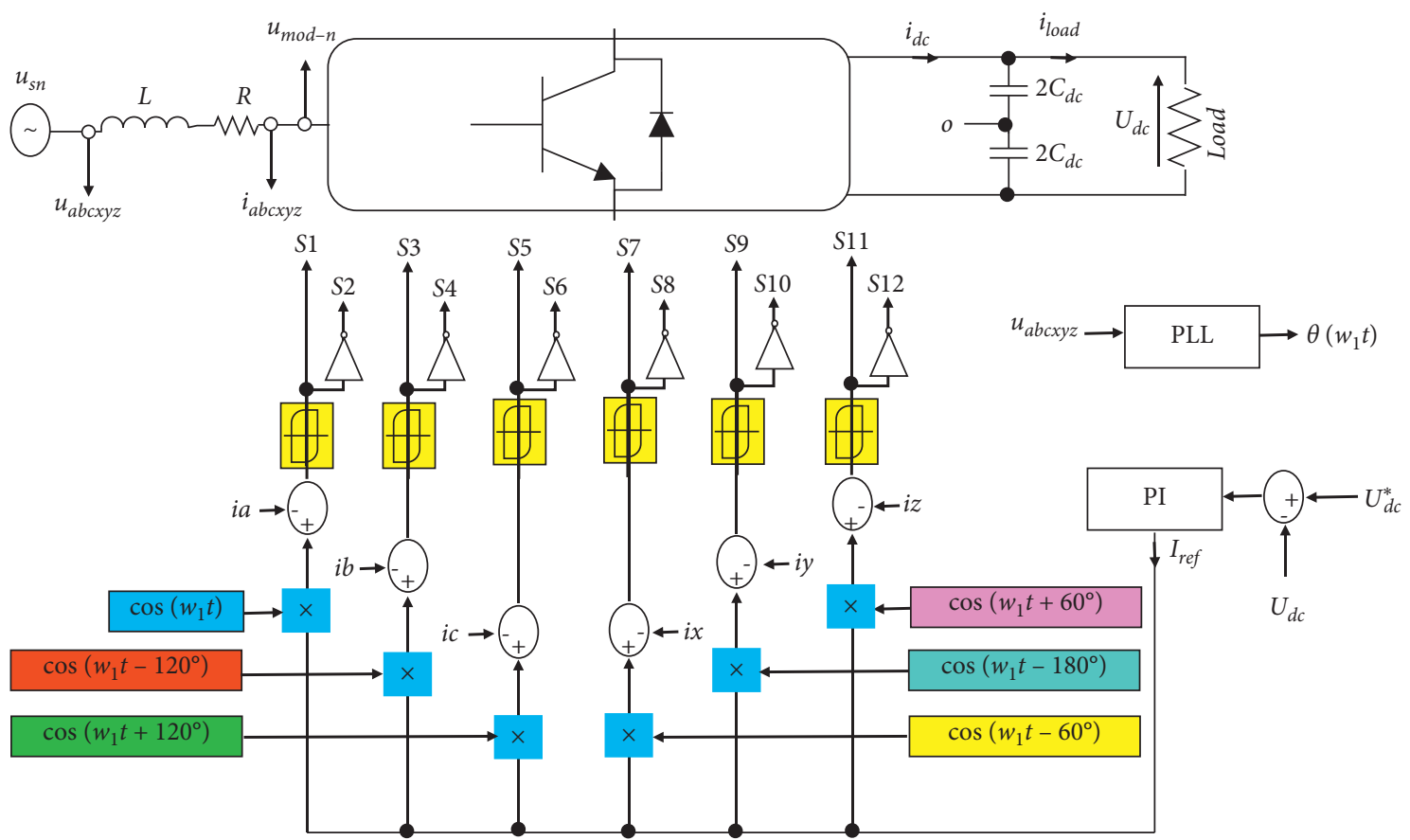

FIGURE 3: Control block diagram of direct current control utilizing hysteresis controller in a six-phase AC-DC converter. 


$$
\begin{aligned}
& T_{62}=\frac{2}{6}\left[\begin{array}{cccccc}
\cos (\theta) & \cos \left(\theta-\frac{2 \pi}{3}\right) & \cos \left(\theta+\frac{2 \pi}{3}\right) & \cos \left(\theta-\frac{\pi}{3}\right) & \cos (\theta-\pi) & \cos \left(\theta+\frac{\pi}{3}\right) \\
-\sin (\theta) & -\sin \left(\theta-\frac{2 \pi}{3}\right) & -\sin \left(\theta+\frac{2 \pi}{3}\right) & -\sin \left(\theta-\frac{\pi}{3}\right) & -\sin (\theta-\pi) & -\sin \left(\theta+\frac{\pi}{3}\right)
\end{array}\right],
\end{aligned}
$$

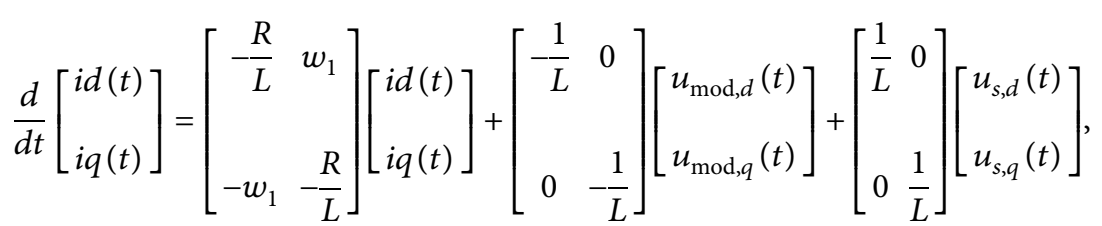

where $w_{1}$ is the angular frequency and $i_{d}$ and $i_{q}$ are d-axis and q-axis currents, respectively. $u_{s d}$ and $u_{s q}$ are d-axis and $\mathrm{q}$-axis voltages, respectively. Source power $\left(P_{s}\right)$ is considered based on equation (3). A part of the source power is dissipated as losses in the converter $\left(P_{\text {losses }}\right)$ and the rest is delivered to the load $\left(P_{\text {load }}\right)$.

$$
P_{s}=P_{\text {load }}+P_{\text {losses }}=3\left(u_{s, d} \cdot i_{d}+u_{s, q} \cdot i_{q}\right) \text {. }
$$

\section{Diagnosis of Open-Switch Faults}

The open-switch faults in the six-phase AC-DC PWM converters have different current patterns compared to the six-phase voltage source inverters. Unlike inverters, these converters do not completely block positive and negative currents during open-switch faults. As shown in Figure 2, in normal operation, the positive half-cycle current is established through the bottom switch and the upper antiparallel diode of one phase, whereas the upper switch and the bottom antiparallel diode of that phase establish the negative halfcycle current. Therefore, if an open-switch fault occurs on the upper switch, the negative half-cycle of phase current is distorted but its positive half-cycle is not affected. On the contrary, if an open-switch fault occurs in the bottom switch, the negative half-cycle of phase current is not affected but its positive half-cycle is distorted. Hence, the open-switch faults can be detected by monitoring the lost part of the phase current [32].

Open-switch faults include single and multiple faults. Two different cases are considered for the multiple openswitch faults:

Case I: the open-switch fault occurs in two switches from two different legs

Case II: the open-switch fault occurs in two switches from one leg

3.1. Single Open-Switch Fault. Due to the open-switch fault that occurred in the upper or bottom switch, part of the negative or positive half-cycle current of that leg is eliminated, which is different from its corresponding reference signal. Therefore, the difference between the phase current and the corresponding reference is used as a fault diagnosis indicator. This fault diagnosis indicator does not require additional measurements so it is integrated with the control block diagram of converter, as shown in Figure 3. The fault diagnosis indicator is normalized to be independent of the load [38].

The first fault diagnosis indicator is normalized residual current $\mathrm{Nr}_{n}$. As shown in (4), $\mathrm{Nr}_{n}$ is the average value of the absolute current error divided by the absolute current value. in and $i{ }^{*}$ are the current and its reference value of each phase, respectively. $\delta$ is a small positive quantity.

$$
\mathrm{Nr}_{n}=\left\langle\frac{\left|i_{n}-i_{n}^{*}\right|}{\delta+\left|i_{n}\right|}\right\rangle \quad n=a, b, c, x, y, z .
$$

In normal conditions, the value of $\mathrm{Nr}_{n}$ is approximately equal to zero in all phases. When the fault occurs, $\mathrm{Nr}_{n}$ of the corresponding phase will change and exceed the threshold value. A good threshold value is essential for a robust fault diagnosis [38]. If the fixed threshold value is high or low, then the fault sensitivity is reduced or the false alarm rate is increased, respectively. Therefore, an adaptive threshold value is the best alternative. According to equation (6), the adaptive threshold value is the average of $R_{\max }$ and $R_{\min }$. In this equation, $R_{\max }$ is the maximum of $\mathrm{Nr}_{n}$ in all phases, and $R_{\min }$ is the minimum of $N r_{n}$ in all phases.

$$
\begin{aligned}
T & =\frac{R_{\max }+R_{\min }}{2}, \\
R_{\max } & =\max \left\{\mathrm{Nr}_{a}, \mathrm{Nr}_{b}, \mathrm{Nr}_{c}, \mathrm{Nr}_{x}, \mathrm{Nr}_{y}, \mathrm{Nr}_{z}\right\}, \\
R_{\min } & =\min \left\{\mathrm{Nr}_{a}, \mathrm{Nr}_{b}, \mathrm{Nr}_{c}, \mathrm{Nr}_{x}, \mathrm{Nr}_{y}, \mathrm{Nr}_{z}\right\} .
\end{aligned}
$$

Under normal conditions, the adaptive threshold value is similar to the value of $\mathrm{Nr}_{n}$, which is approximately equal to zero. Nevertheless, in fault conditions, due to a sudden change in the value of $\mathrm{Nr}_{n}$, the value of $R_{\max }$ increases. As a result, the adaptive threshold value also increases and becomes greater than zero [35]. Since $T$ is the average value of $R_{\max }$ and $R_{\min }$, so it is smaller than $N r_{n}$ in the faulty phase. Moreover, as $\mathrm{Nr}_{n}$ has not changed in other phases, their value has become less than $T$. The phase with the single open-switch fault is detected by considering the first fault diagnosis indicator $\left(\mathrm{Nr}_{n}\right)$ and the adaptive threshold value (T) according to Table 1. 
TABLe 1: The different states of the single open-switch fault diagnosis.

\begin{tabular}{llllll}
\hline Normal condition & $\mathrm{Nr}_{a} \approx T$ & $\mathrm{Nr}_{b} \approx T$ & $\mathrm{Nr}_{c} \approx T$ & $\mathrm{Nr}_{x} \approx T$ & $\mathrm{Nr}_{y} \approx T$ \\
\hline Fault in phase a & $\mathrm{Nr}_{a}>T$ & $\mathrm{Nr}_{b}<T$ & $\mathrm{Nr}_{c}<T$ & $\mathrm{Nr}_{x}<T$ & $\mathrm{Nr}_{y} \approx T$ \\
Fault in phase b & $\mathrm{Nr}_{a}<T$ & $\mathrm{Nr}_{b}>T$ & $\mathrm{Nr}_{c}<T$ & $\mathrm{Nr}_{x}<T$ & $\mathrm{Nr}_{y}<T$ \\
Fault in phase c & $\mathrm{Nr}_{a}<T$ & $\mathrm{Nr}_{b}<T$ & $\mathrm{Nr}_{c}>T$ & $\mathrm{Nr}_{x}<T$ & $\mathrm{Nr}_{z}<T$ \\
Fault in phase x & $\mathrm{Nr}_{a}<T$ & $\mathrm{Nr}_{b}<T$ & $\mathrm{Nr}_{c}<T$ & $\mathrm{Nr}_{x}>T$ & $\mathrm{Nr}_{z}<T$ \\
Fault in phase y & $\mathrm{Nr}_{a}<T$ & $\mathrm{Nr}_{b}<T$ & $\mathrm{Nr}_{c}<T$ & $\mathrm{Nr}_{x}<T$ & $\mathrm{Nr}_{z}>T$ \\
Fault in phase z & $\mathrm{Nr}_{a}<T$ & $\mathrm{Nr}_{b}<T$ & $\mathrm{Nr}_{c}<T$ & $\mathrm{Nr}_{x}<T$ & $\mathrm{Nr}_{z}<T$ \\
\hline
\end{tabular}

As shown in Figure 2, each phase has two switches. After detecting the faulty phase, it is necessary to determine whether the open-switch fault occurred in the upper switch or the bottom one. Therefore, the average current value $<$ in $>$ is considered as another indicator of open-switch fault diagnosis to distinguish between the upper and bottom switch. If the value of $\langle i n>$ is higher than zero, the open-switch fault has occurred in the upper switch. Hence, the open-switch fault has occurred in the bottom switch when $\langle i n>$ is lower than zero. The block diagram of the open-switch fault based on the two indicators $\mathrm{Nr}_{n}$ and $\langle i n>$ is presented in Figure 4.

3.2. Multiple Open-Switch Faults. Multiple open-switch faults occur in at least two switches of one leg or two different legs. The value of $\mathrm{Nr}_{n}$ in the faulty phases is greater than the adaptive threshold while it is smaller in healthy phases. For example in Figure 2, if $S_{2}$ and $S_{11}$ are in a faulty state, $i_{a}$ and $i_{z}$ will lose their positive and negative half-cycles, respectively. Accordingly, $\mathrm{Nr}_{a}$ and $\mathrm{Nr}_{z}$ are greater than $T$ whereas $\mathrm{Nr}_{b}, \mathrm{Nr}_{c}, \mathrm{Nr}_{x}$, and $\mathrm{Nr}_{y}$ are smaller than $T$. Similar to the single open-switch fault, the average current value is used to discern the upper switch from the bottom switch in multiple open-switch fault modes. Therefore, $\left\langle i_{a}\right\rangle$ is smaller than zero because $S_{2}$ is the bottom switch and $\left\langle i_{z}\right\rangle$ is larger than zero because $S_{11}$ is the upper switch.

When multiple open-switch faults occur in the upper and the bottom switches from one leg, only the value of $\mathrm{Nr}_{n}$ in that phase is greater than the adaptive threshold, similar to the single open-switch fault. In this case, the average current value is used to distinguish between single and multiple open-switch faults of a leg. In a single open-switch fault condition, the value of $\left\langle i_{n}\right\rangle$ in the faulty phase is greater than zero or smaller than zero, while in multiple open-switch faults on both switches of one leg, the value of $\left\langle i_{n}\right\rangle$ becomes approximately equal to zero after a considerable fluctuation.

\section{The Proposed Fault-Tolerant Method for Open-Switch Faults}

Open-switch faults in the six-phase converters do not immediately cause the system to shut down, but they compromise the performance of the converters. To improve the converter's performance and prevent secondary fault, the fault-tolerant control takes place. Figure 5 shows the sixphase currents of the AC-DC converter in the normal operation, which is similar to the voltage waveform due to the unity power factor. The general equation of the current is as follows:

$$
\mathrm{i}_{k}=I_{m} \cos \left(w_{1} t-\frac{(k-1) * \pi}{3}\right) \quad k=1,2, \ldots 6,
$$

where $I m$ is the six-phase current amplitude and $w_{1}$ is the angular frequency. Every cycle of the currents can be divided into 12 regions, where their corresponding devices with normal operation are presented in Table 2. According to Table 2, under normal conditions in each region, three of the upper switches of each phase and three of the bottom switches of the other phases conduct currents.

According to Kirchhoff's circuit laws, the sum of the sixphase currents should be zero. Since the faulty switch is unable to conduct its corresponding half-cycle current, this current is imposed to the side phases, thus causing an overcurrent. For each side phase, the overcurrent can be calculated by

$$
\begin{aligned}
& i_{f a u l t(k-1)}=I_{m} \cos \left(w_{1} t-\frac{(k-2) * \pi}{3}\right)+I_{m} \cos \left(w_{1} t-\frac{(k-1) * \pi}{3}\right)=\sqrt{3} * I_{m} \cos \left(w_{1} t-\frac{(k-2) \pi}{3}+\frac{\pi}{6}\right) \\
& i_{f a u l t(k+1)}=I_{m} \cos \left(w_{1} t-\frac{k \pi}{3}\right)+I_{m} \cos \left(w_{1} t-\frac{(k-1) * \pi}{3}\right)=\sqrt{3} * I_{m} \cos \left(w_{1} t-\frac{k \pi}{3}+\frac{\pi}{6}\right)
\end{aligned}
$$

where $k$ is the faulty phase and ifault is the fault current. Therefore, the amplitude of the overcurrent is more than $73 \%$ of the rated phase current, which causes terrible stresses on the switches of these phases. Accordingly, there is a high possibility of secondary faults in the converter system, and the proposed fault-tolerant control should limit this overcurrent in other healthy phases.
4.1. Fault-Tolerant Method for a Single Open-Switch Fault. According to Figure 5 and equation (6), the currents of phases $A, B$, and $C$ are symmetrical with the currents of phases $Y, Z$, and $X$, respectively. In other words, phase $Y$ is the opposite phase of phase $A$, phase $Z$ is the opposite phase of phase $B$, and phase $X$ is the opposite phase of phase $C$. Then, the overcurrent in healthy phases can be limited by turning off the 


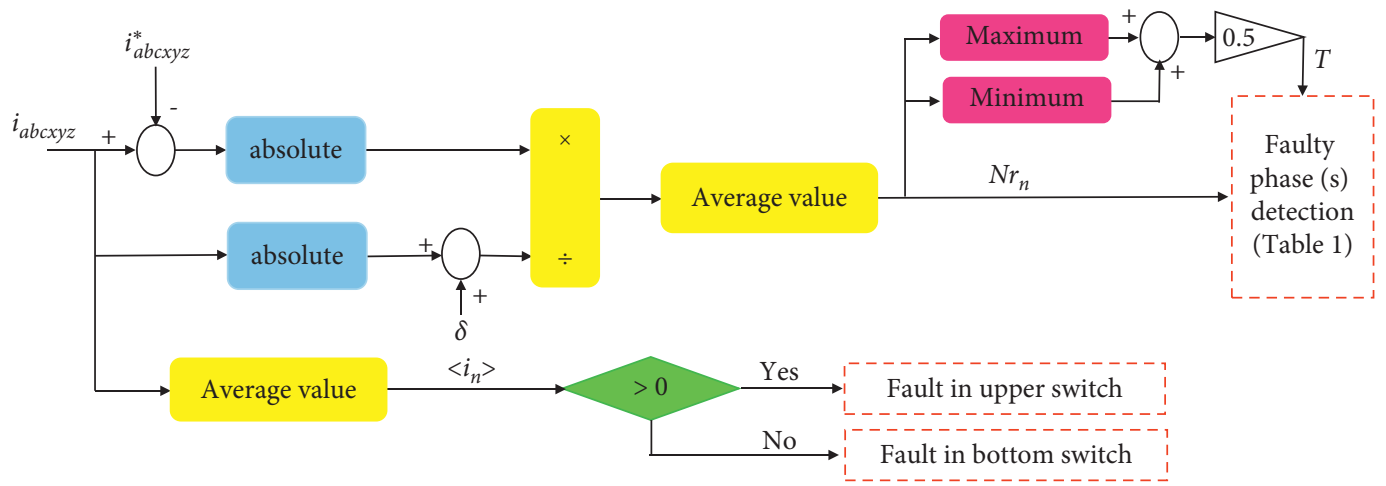

FIGURE 4: Block diagram of the open-switch fault detection method.

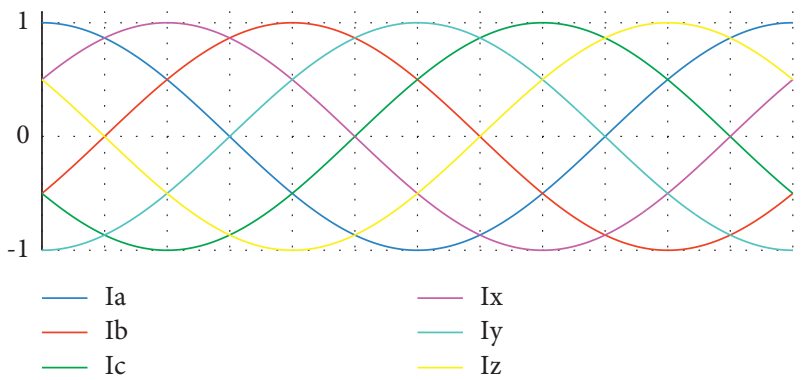

FIGURE 5: Six-phase currents of AC-DC converter at normal operation.

TABLE 2: Conducting diodes and switches of the six-phase converter at normal operation.

\begin{tabular}{lcr}
\hline Regions & Conducting switches & Conducting diodes \\
\hline Reg1: $\left(0-\frac{\pi}{6}\right)$ & $S_{2}, S_{3}, S_{5}, S_{8}, S_{9}, S_{12}$ & $D_{1}, D_{4}, D_{6}, D_{7}, D_{10}, D_{11}$ \\
Reg2: $\left(\frac{\pi}{6}-\frac{2 \pi}{6}\right)$ & $S_{2}, S_{4}, S_{5}, S_{8}, S_{9}, S_{11}$ & $D_{1}, D_{3}, D_{6}, D_{7}, D_{10}, D_{12}$ \\
Reg3: $\left(\frac{2 \pi}{6}-\frac{\pi}{2}\right)$ & $S_{2}, S_{4}, S_{5}, S_{8}, S_{9}, S_{11}$ & $D_{1}, D_{3}, D_{6}, D_{7}, D_{10}, D_{12}$ \\
Reg4: $\left(\frac{\pi}{2}-\frac{4 \pi}{6}\right)$ & $S_{1}, S_{4}, S_{5}, S_{8}, S_{10}, S_{11}$ & $D_{2}, D_{3}, D_{6}, D_{7}, D_{9}, D_{12}$ \\
Reg5: $\left(\frac{4 \pi}{6}-\frac{5 \pi}{6}\right)$ & $S_{1}, S_{4}, S_{5}, S_{8}, S_{10}, S_{11}$ & $D_{2}, D_{3}, D_{6}, D_{7}, D_{9}, D_{12}$ \\
Reg6: $\left(\frac{5 \pi}{6}-\pi\right)$ & $S_{1}, S_{4}, S_{6}, S_{7}, S_{10}, S_{11}, D_{2}, D_{3}, D_{5}, D_{8}, D_{9}, D_{12}$ \\
Reg7: $\left(\pi-\frac{7 \pi}{6}\right)$ & $S_{1}, S_{4}, S_{6}, S_{7}, S_{10}, S_{11}$ & $D_{2}, D_{3}, D_{5}, D_{8}, D_{9}, D_{12}$ \\
Reg8: $\left(\frac{7 \pi}{6}-\frac{8 \pi}{6}\right)$ & $S_{1}, S_{3}, S_{6}, S_{7}, S_{10}, S_{12}$ & $D_{2}, D_{4}, D_{5}, D_{8}, D_{9}, D_{11}$ \\
Reg9: $\left(\frac{8 \pi}{6}-\frac{3 \pi}{2}\right)$ & $S_{1}, S_{3}, S_{6}, S_{7}, S_{10}, S_{12}$ & $D_{2}, D_{4}, D_{5}, D_{8}, D_{9}, D_{11}$ \\
Reg10: $\left(\frac{3 \pi}{2}-\frac{10 \pi}{6}\right)$ & $S_{2}, S_{3}, S_{6}, S_{7}, S_{9}, S_{12}$ & $D_{1}, D_{4}, D_{5}, D_{8}, D_{10}, D_{11}$ \\
Reg11: $\left(\frac{10 \pi}{6}-\frac{11 \pi}{6}\right)$ & $S_{2}, S_{3}, S_{6}, S_{7}, S_{9}, S_{12}$ & $D_{1}, D_{4}, D_{5}, D_{8}, D_{10}, D_{11}$ \\
Reg12: $\left(\frac{11 \pi}{6}-2 \pi\right)$ & $S_{2}, S_{3}, S_{5}, S_{8}, S_{9}, S_{12}$ & $D_{1}, D_{4}, D_{6}, D_{7}, D_{10}, D_{11}$ \\
\hline
\end{tabular}

switches in the opposite phase of the faulty ones, in some regions. The fault-tolerant switch and fault-tolerant regions for every single open-switch fault are described in Table 3. For example, in Figure 2, if an open-switch fault occurs on the $S_{11}$ switch, the negative half-cycle current of phase $Z$ does not pass through this switch and causes overcurrent in phases $A$ and $C$. According to Table 3 , the $S_{4}$ switch in the opposite phase of phase $Z$ must be turned off in regions $2,3,6$, and 7 to reduce the overcurrent in healthy phases $A$ and $C$.

4.2. Fault-Tolerant Method for Multiple Open-Switch Faults. After fault detection and localization in multiple open-switch faults, the proposed fault-tolerant control for both faulty switches is simultaneously performed according to Table 3. The open-switch fault of switches $S_{1}$ and $S_{12}$ in Figure 2 is considered as an example. These multiple open-switch faults cause overcurrent in the negative half-cycle current of phases $X$ and $Z$ and the positive half-cycle current of phases $A$ and $C$. The overcurrent in healthy phases is limited by turning off $S_{10}$ in regions $4,5,8$, and 9 and simultaneously $S_{3}$ in regions 1,8 , 9 , and 12 . To evaluate the effectiveness of the proposed faulttolerant method, an overcurrent indicator $\left(I_{o v}\right)$ in the side phases of the faulty one is defined according to equation (9). This method tries to reduce it.

$$
I_{\text {ov }(k \pm 1)}=\max \frac{\left|i_{\text {fault }(k \pm 1)}-i_{\text {normal }(k \pm 1)}\right|}{\left|i_{\text {normal }(k \pm 1)}\right|},
$$

where $k$ is the faulty phase and $k \pm 1$ are the side phases. ifault and inormal are the phase current in faulty and healthy conditions. 
TABLE 3: Fault-tolerant switch and fault-tolerant regions for six-phase AC-DC converter at open-switch fault conditions.

\begin{tabular}{lcr}
\hline Open-switch fault & Fault-tolerant switch & Fault-tolerant regions \\
\hline$S_{1}$ & $S_{10}$ & Reg4, Reg5, Reg8, Reg9 \\
$S_{2}$ & $S_{9}$ & Reg2, Reg3, Reg10, Reg11 \\
$S_{3}$ & $S_{12}$ & Reg1, Reg8, Reg9, Reg12 \\
$S_{4}$ & $S_{11}$ & Reg2, Reg3, Reg6, Reg7 \\
$S_{5}$ & $S_{8}$ & Reg1, Reg4, Reg5, Reg12 \\
$S_{6}$ & $S_{7}$ & Reg6, Reg7, Reg10, Reg11 \\
$S_{7}$ & $S_{6}$ & Reg6, Reg7, Reg10, Reg11 \\
$S_{8}$ & $S_{5}$ & Reg1, Reg4, Reg5, Reg12 \\
$S_{9}$ & $S_{2}$ & Reg2, Reg3, Reg10, Reg11 \\
$S_{10}$ & $S_{1}$ & Reg4, Reg5, Reg8, Reg9 \\
$S_{11}$ & $S_{4}$ & Reg2, Reg3, Reg6, Reg7 \\
$S_{12}$ & $S_{3}$ & Reg1, Reg8, Reg9, Reg12 \\
\hline
\end{tabular}

\section{Simulation Results}

To evaluate the performances of the proposed fault detection method and fault-tolerant control in the six-phase AC-DC converter, several simulations are carried out by using the MATLAB/Simulink software. The simulation parameters and open-switch fault conditions are given in Table 4. Although the fault-tolerant technique can be performed immediately after fault detection, it is performed after a while (at $t=0.3 \mathrm{~s}$ ) to make its effect more clear. The simulation results are divided into three-time intervals:

(1) Normal condition: $t<0.2 \mathrm{~s}$

(2) Open-switch fault time: $0.2 \mathrm{~s}<t<0.3 \mathrm{~s}$

(3) Fault-tolerant time: $t>0.3 \mathrm{~s}$

Firstly, the robustness of the fault detection method against load changes should be evaluated. According to Figure 6(a), assume that the load connected to the converter is halved at $t=0.14 \mathrm{~s}$. As shown in Figure 6(b), the load changes affect all the phases and increase the value of $N r_{n}$ and $T$, but they stay close to each other. Therefore, the fault detection method correctly identifies such changes as nonfault conditions and it is robust against them.

According to Figure 7(a), an open-switch fault has occurred in the switch $S 11$ in at the moment $t=0.2 \mathrm{~s}$, which has caused a disturbance in the six-phase currents. Part of the negative half-cycle current of phase $Z$ is eliminated, while phases $A$ and $C$ suffer 66 percent overcurrent.

Under normal conditions, the values of the actual and reference currents are close to each other, so the values of $\mathrm{Nr}_{n}$ and $T$ are about zero. After the start time of the single open-switch fault, the values of $\mathrm{Nr}_{n}$ in the faulty phase will increase, and consequently, the value of $T$ will increase. Since $\left(T>\mathrm{Nr}_{a}\right),\left(T>\mathrm{Nr}_{b}\right),\left(T>\mathrm{Nr}_{c}\right),\left(T>\mathrm{Nr}_{x}\right),\left(T>\mathrm{Nr}_{y}\right)$ and $\left(T<\mathrm{Nr}_{z}\right)$, the open-switch fault is detected in phase $Z$ at $T f d=0.2023 \mathrm{~s}$ according to Table 1 and Figure 8 . As shown in Figure 9, the value of $\langle i z\rangle$ is greater than zero, so the openswitch fault occurred in the upper switch of phase $Z$.

After identifying the faulted switch S11, the fault-tolerant control is executed at $t=0.3 \mathrm{~s}$, according to Table 3 . As shown in Figure 7(b), during the open-switch fault of the $S 11$, the $S 4$ switch is turned off in regions $2,3,6$, and 7 , to reduce the overcurrent of phases $A$ and $C$. By applying the fault-tolerant method, in addition to reducing the overcurrent in phases $A$ and $C$, the THD of current in these phases is also reduced. The THD of phases $A$ and $C$ is presented in Figure 10. The numerical results of the overcurrent indicator and THD for the side phases of the faulty phase at the open-switch fault time and fault-tolerant time are presented in Table 5.

Since a fault on any switch may also cause other switches to fail, multiple switch faults are very significant and should be addressed properly. For example, consider the open-switch faults on switches $S 1$ and $S 12$ that cause an overcurrent in the negative half-cycle of phases $X$ and $Z$ and the positive half-cycle of phases $A$ and $C$, respectively. As shown in Figure 11(a) and Table 5, the value of overcurrent will be reduced by turning off $S_{10}$ in regions 4 , 5,8 , and 9 and $S_{3}$ in regions $1,8,9$, and 12 . This reduction in the side phases $A$ and $C$ after implementing the faulttolerant method is specifically shown in Figure 11(b). According to Figure 12 and Table 5, the THD of current in healthy phases is reduced by executing the fault-tolerant method.

Multiple open-switch faults occur when the value of $\mathrm{Nr}_{n}$ in more than one phase is greater than the value of $T$ while in the other phases it is smaller than the value of $T$. According to Figure 13, when $\left(T>\mathrm{Nr}_{b}\right),\left(T>\mathrm{Nr}_{c}\right),\left(T>\mathrm{Nr}_{x}\right),(T>$ $\left.\mathrm{Nr}_{y}\right)\left(T<\mathrm{Nr}_{a}\right)$, and $\left(T<\mathrm{Nr}_{z}\right)$, the open-switch faults occurred in phases $A$ and $Z$ at $T f d=0.2062 \mathrm{~s}$. The value of $\langle i a\rangle$ is greater than zero and the value of $\langle i z\rangle$ is smaller than zero; therefore, the open-switch faults occurred in the upper switch of phase $A(S 1)$ and the bottom switch of phase $Z$ (S12), as shown in Figure 14 .

In cases where multiple open-switch faults occur in both switches of one leg, the value of $\mathrm{Nr}_{n}$ in that phase is greater than the value of $T$. However, unlike a single open-switch fault, the value of $\langle i n>$ does not remain positive or negative and after a significant fluctuation becomes approximately zero again. The values $\mathrm{Nr}_{n}$ and $\langle i n\rangle$ are shown in Figures 15 and 16 for multiple open-switch faults in both switches of phase $A$. Since only $\left(T<\mathrm{Nr}_{a}\right)$, the open-switch fault is detected in phase $A$ at $T f d=0.203 \mathrm{~s}$, as shown in Figure 15. According to Figure 16, the value of $\langle i a\rangle$ also came close to zero again at the time of fault.

In fault-tolerant time for open-switch fault in both switches of phase $A$, switches $S_{10}$ and $S_{9}$ must be turned off 
TABle 4: Parameters of the six-phase AC-DC converter simulation.

\begin{tabular}{lccccc}
\hline Input voltage & 6 ph-230 $(\mathrm{v})$ & DC-link voltage & $650(\mathrm{~V})$ & Control format & Hysteresis $(\mathrm{s})$ \\
\hline Grid frequency & $50(\mathrm{~Hz})$ & DC-link capacitance & $2200(\mu \mathrm{F})$ & Fault start time & 0.2 \\
Reactor & $5(\mathrm{mH})$ & DC load resistance & $100(\mathrm{ohm})$ & Tolerant control start time & 0.3 \\
\hline
\end{tabular}
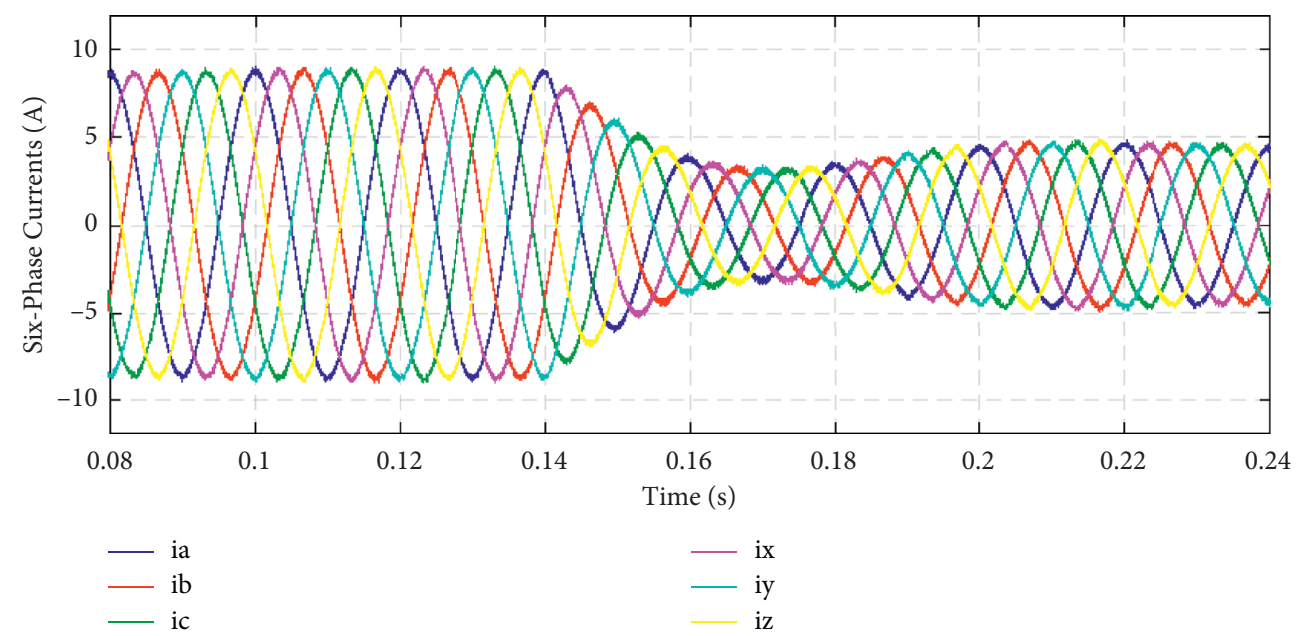

(a)

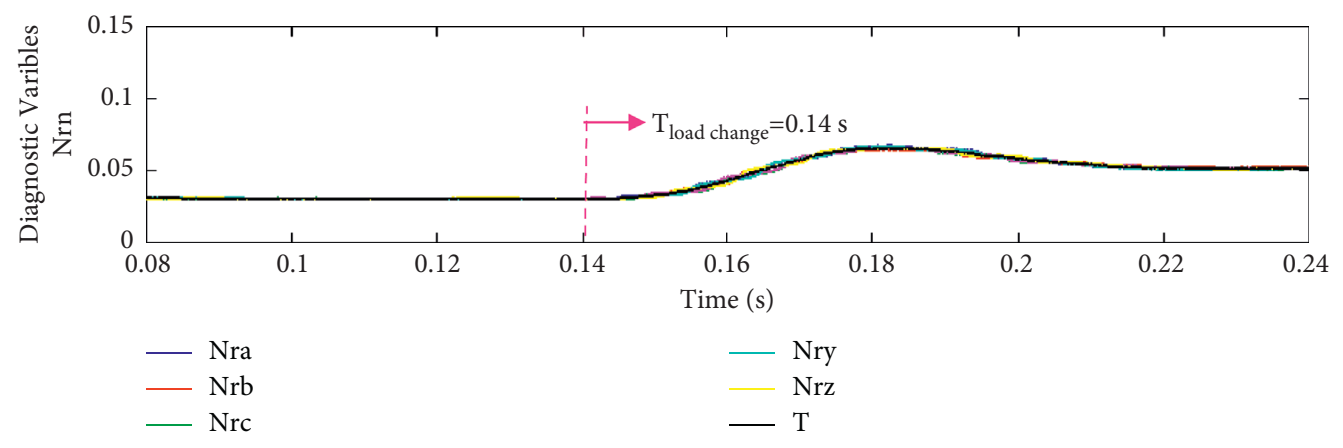

(b)

FiguRe 6: Simulation result to prove the robustness of the fault detection method against load changes. (a) Six-phase currents. (b) Diagnostic variables $N r_{n}$.

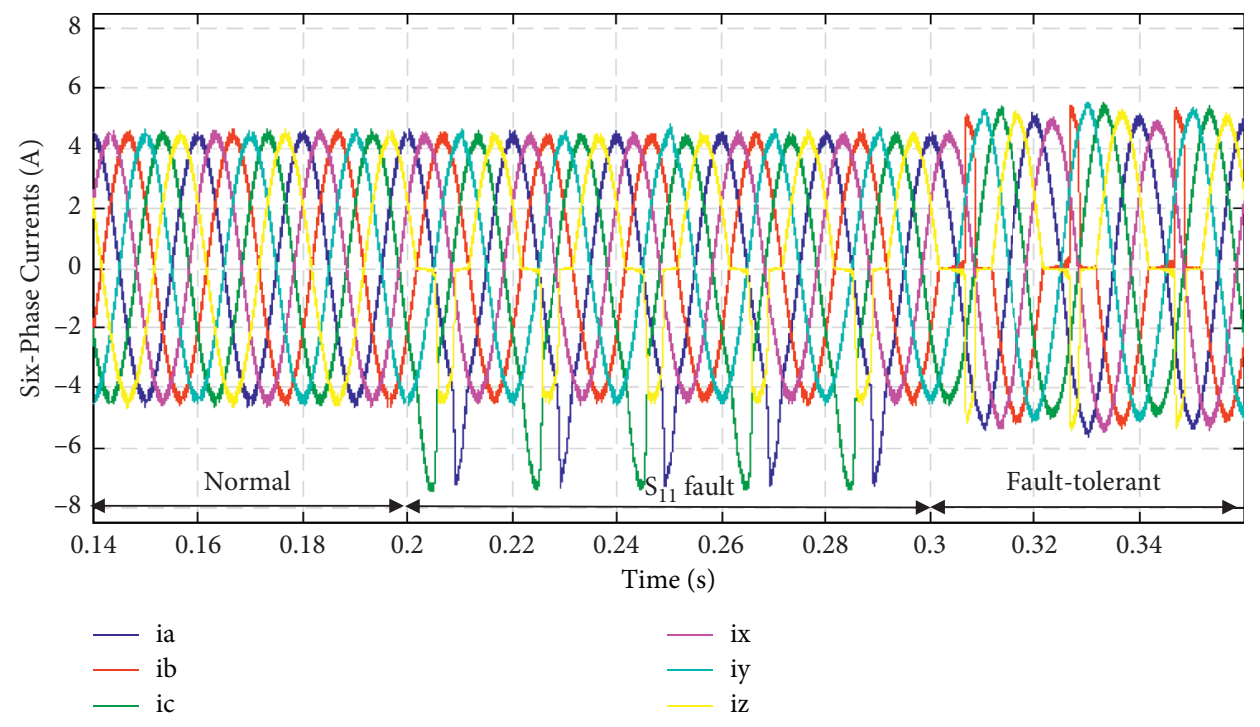

(a)

Figure 7: Continued. 


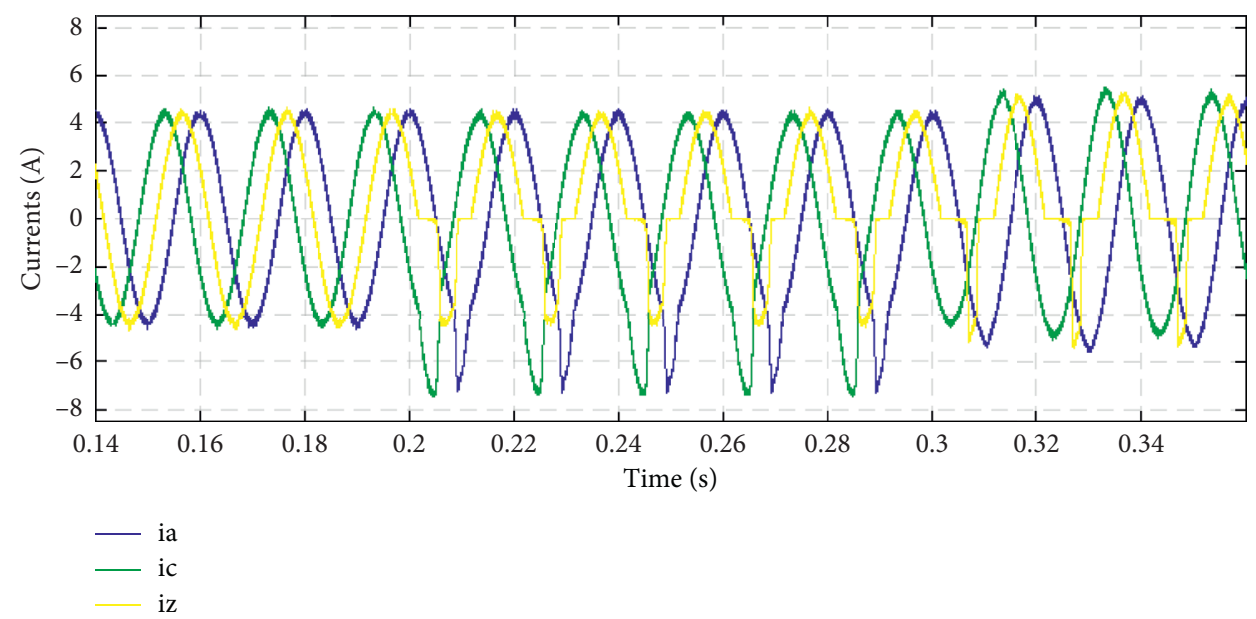

(b)

Figure 7: Simulation result of the AC-DC converter currents before and after open-switch fault in S11. (a) All phases. (b) Faulty phase $Z$ and side phases $A$ and $C$.

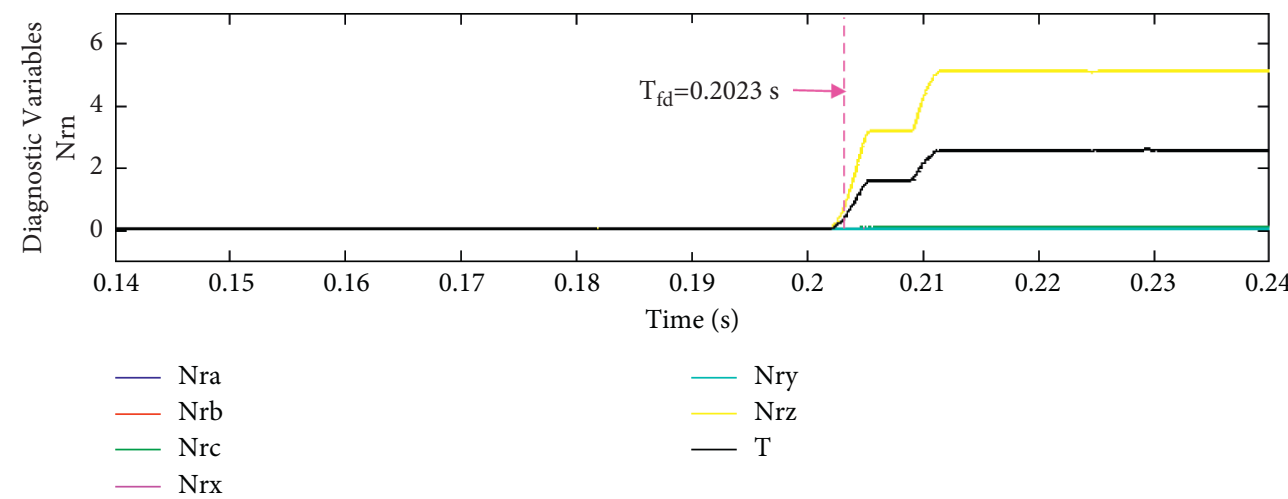

Figure 8: Simulation result of the diagnostic variables Nrn, for open-switch faults in phase $Z$.

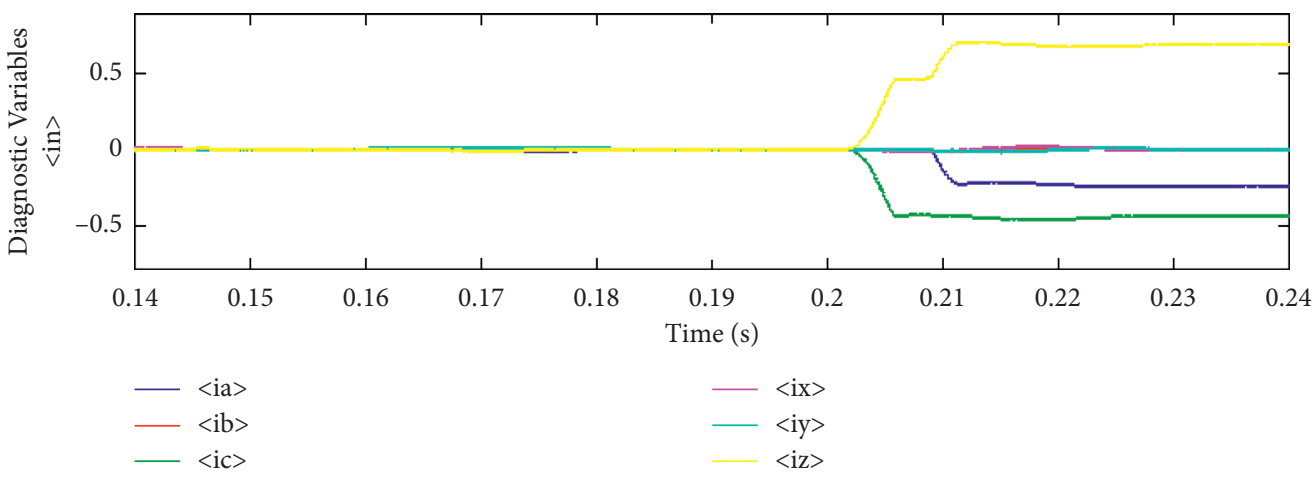

FIGURE 9: Simulation result of the diagnostic variables $\langle i n\rangle$, for open-switch faults in $S_{11}$.

in regions (4, 5, 8, and 9) and (2, 3, 10, and 11), respectively. According to Figure 17, Figure 18, and Table 5, by implementing the fault-tolerant method, the value of overcurrent and THD of current in phases $X$ and $Z$ are reduced.
In both single and multiple open-switch faults, the maximum value of DC-link voltage ripple is 5 volts, which is smaller than $1 \%$ of the reference value. Figure 19 shows the DC-link voltage ripple for single open-switch fault, multiple open-switch faults in two legs, and both switches of one leg, respectively. 


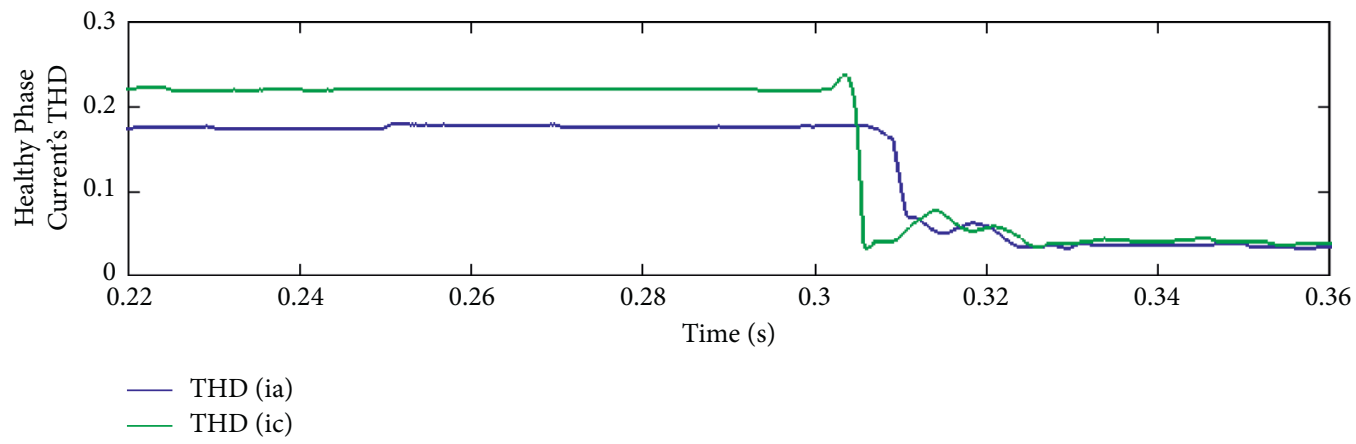

FIgURE 10: Simulation result of the THD of phases A and C, for open-switch fault and fault-tolerant conditions.

TABLE 5: Numerical results of the overcurrent indicator and THD for open-switch fault conditions.

\begin{tabular}{|c|c|c|c|c|c|}
\hline \multirow{2}{*}{ Faulty switch } & \multirow{2}{*}{ Side phase } & \multicolumn{2}{|c|}{ Fault condition } & \multicolumn{2}{|c|}{ Fault-tolerant control } \\
\hline & & $I_{o v}$ & THD & $I_{o v}$ & THD \\
\hline \multirow{2}{*}{$S_{11}$} & $\mathrm{~A}$ & 0.62 & 0.176 & 0.22 & 0.035 \\
\hline & $\mathrm{C}$ & 0.66 & 0.22 & 0.21 & 0.042 \\
\hline \multirow{2}{*}{$S_{1}$ and $S_{12}$} & $\mathrm{X}$ & 0.44 & 0.094 & 0.24 & 0.034 \\
\hline & $\mathrm{C}$ & 0.66 & 0.21 & 0.35 & 0.038 \\
\hline \multirow{2}{*}{$S_{1}$ and $S_{2}$} & $\mathrm{X}$ & 0.60 & 0.21 & 0.35 & 0.036 \\
\hline & $\mathrm{Z}$ & 0.62 & 0.23 & 0.33 & 0.037 \\
\hline
\end{tabular}

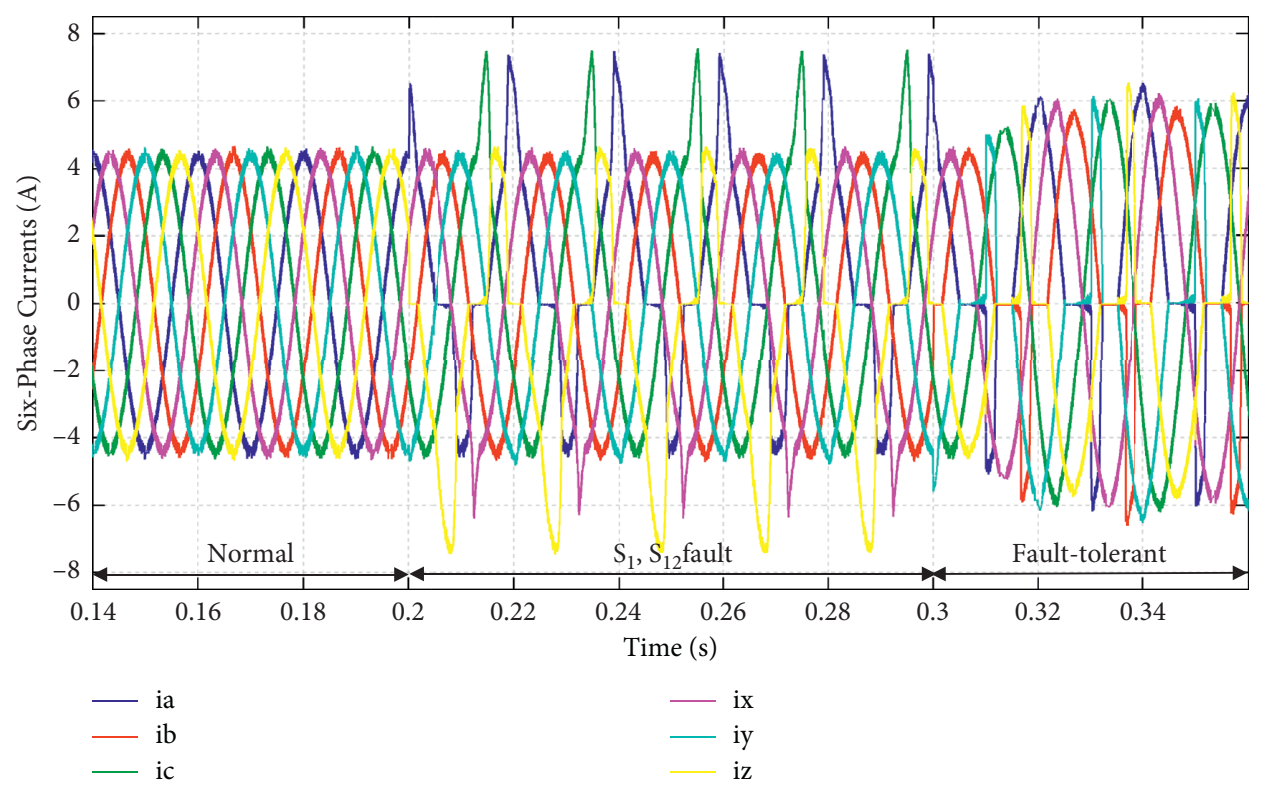

(a)

Figure 11: Continued. 


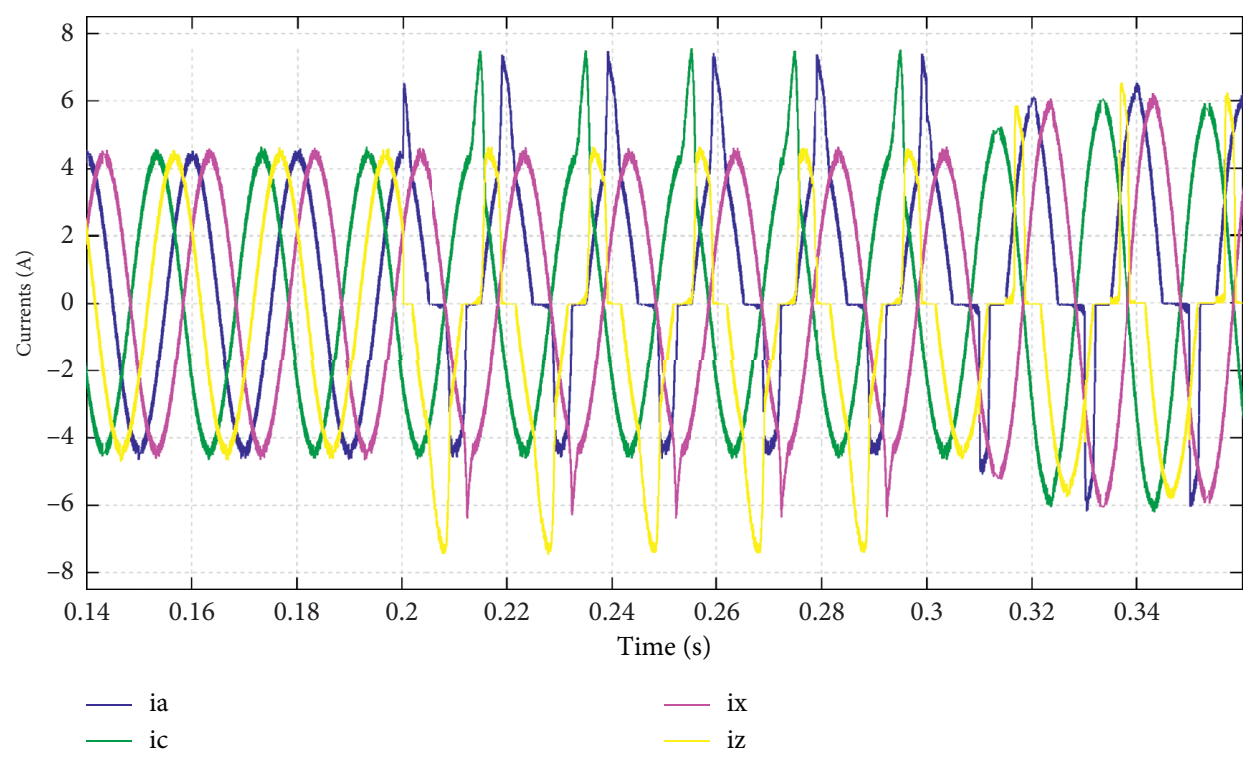

(b)

Figure 11: Simulation result of the AC-DC converter currents before and after multiple open-switch faults in $S_{1}$ and $S_{12}$. (a) All phases. (b) Faulty phases $\mathrm{A}$ and $\mathrm{Z}$ and side phases $\mathrm{X}$ and $\mathrm{C}$.

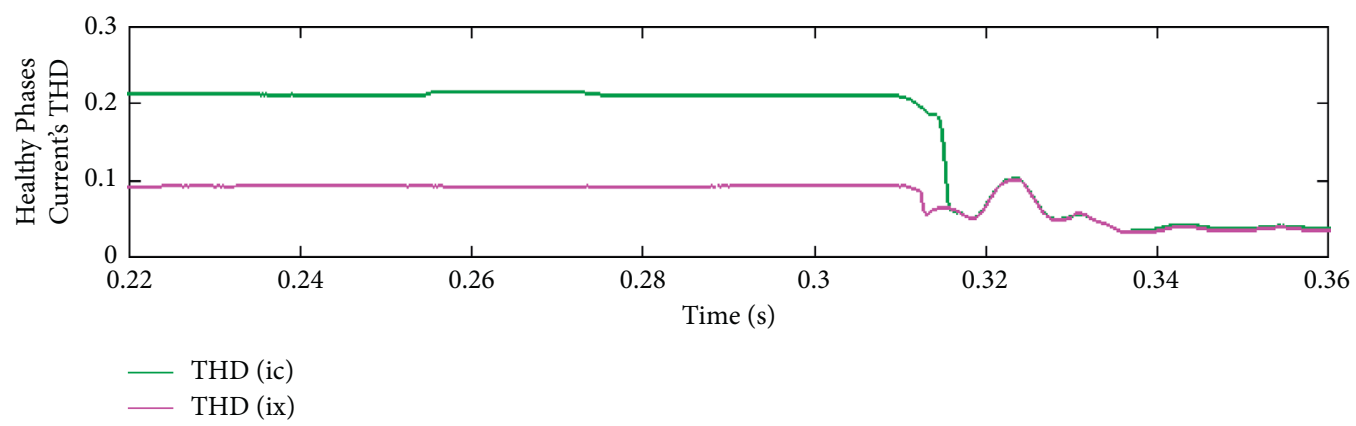

FIgURE 12: Simulation result of the THD of phases $X$ and $C$, for multiple open-switch fault and fault-tolerant conditions.

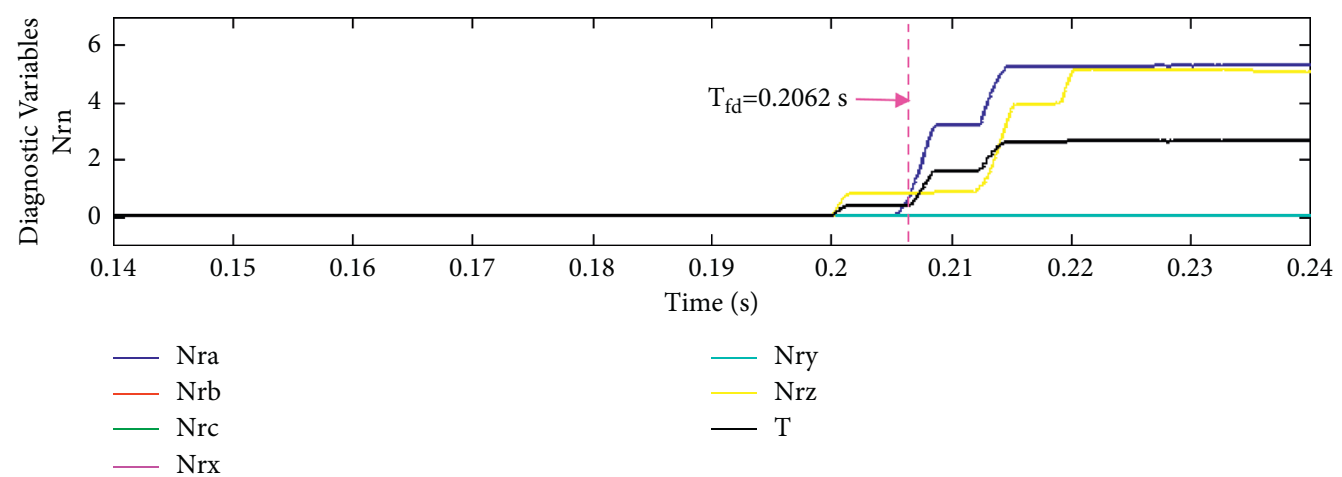

FIgURE 13: Simulation result of the diagnostic variables $\mathrm{Nr}_{n}$, for open-switch faults in phases A and $Z$. 


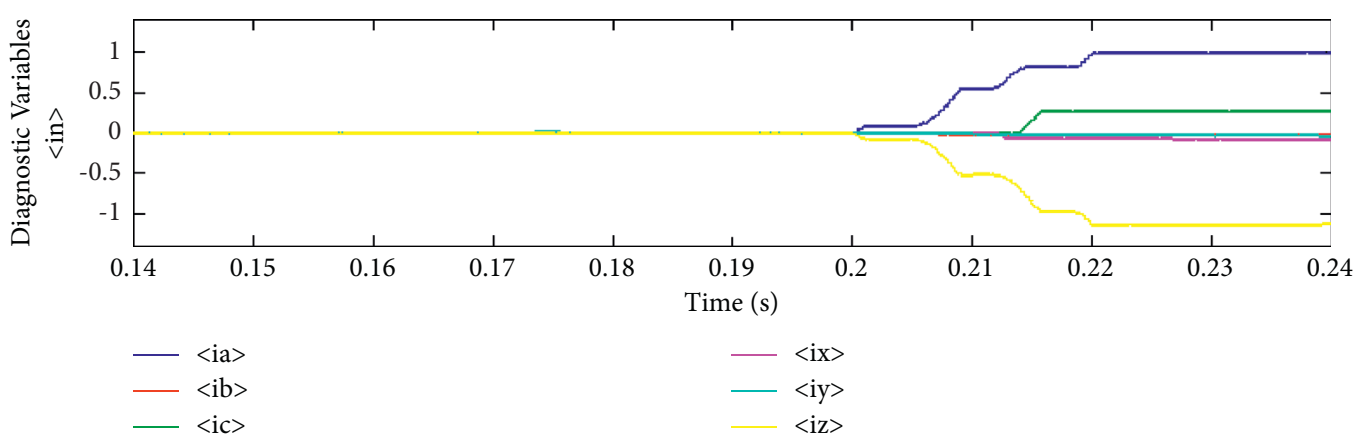

FIgURE 14: Simulation result of the diagnostic variables $\langle i n\rangle$, for open-switch faults in $S_{1}$ and $S_{12}$.

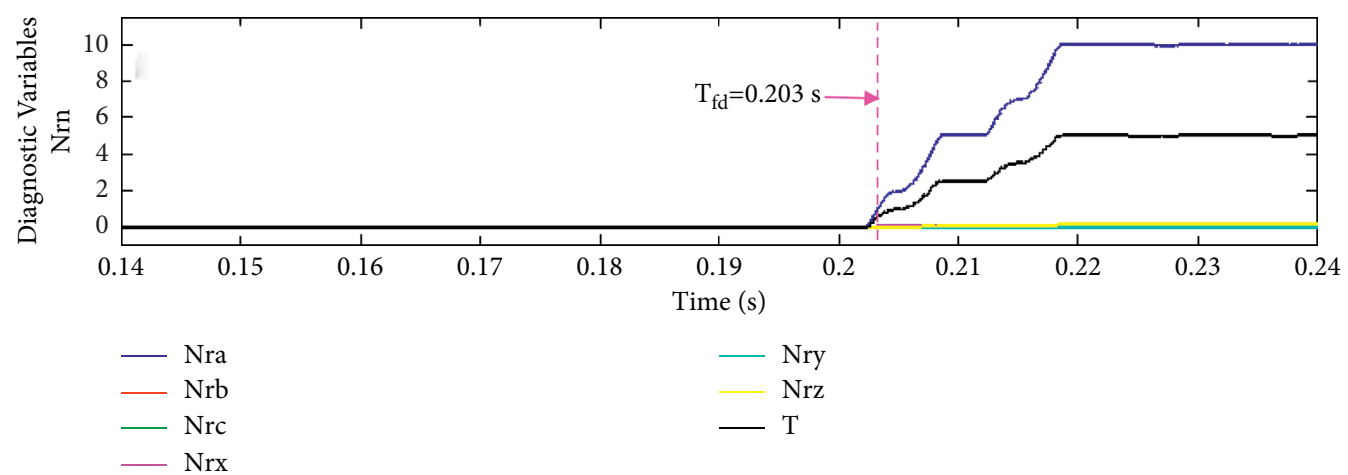

FIGURE 15: Simulation result of the diagnostic variables $\mathrm{Nr}_{n}$, for open-switch faults in both switches of phases A.

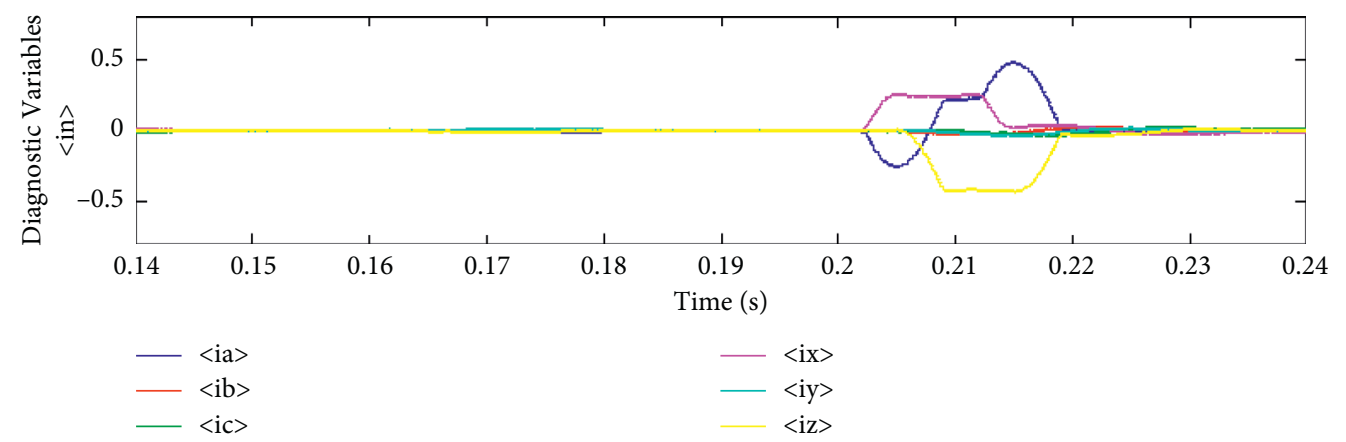

FIGURE 16: Simulation result of the diagnostic variables $\langle i n\rangle$, for multiple open-switch faults in $S_{1}$ and $S_{2}$.

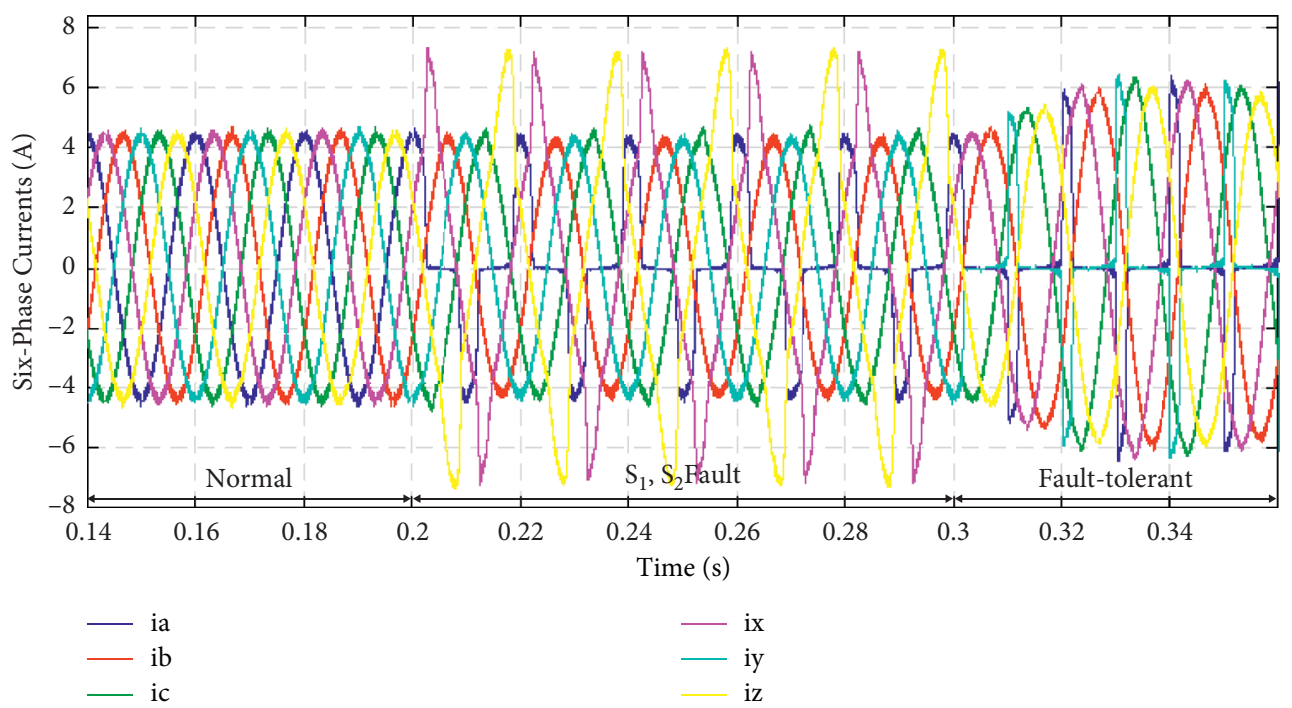

(a)

Figure 17: Continued. 


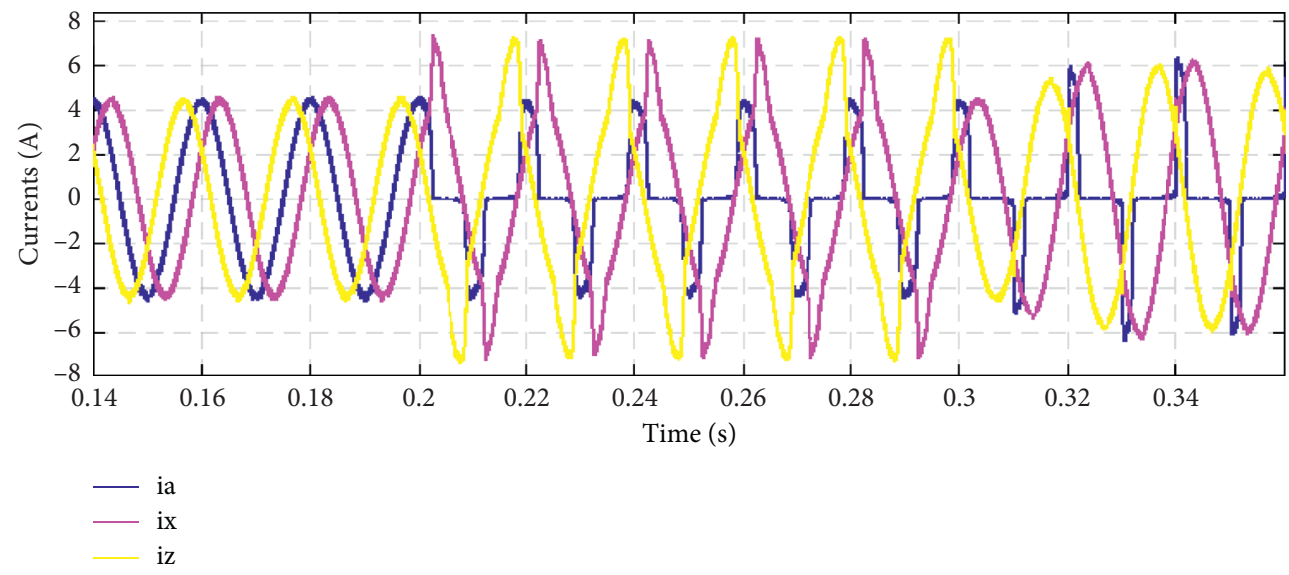

(b)

FIGURE 17: Simulation result of the AC-DC converter currents before and after multiple open-switch faults in both switches of phase A. (a) All phases. (b) Faulty phase A and side phases X and Z.

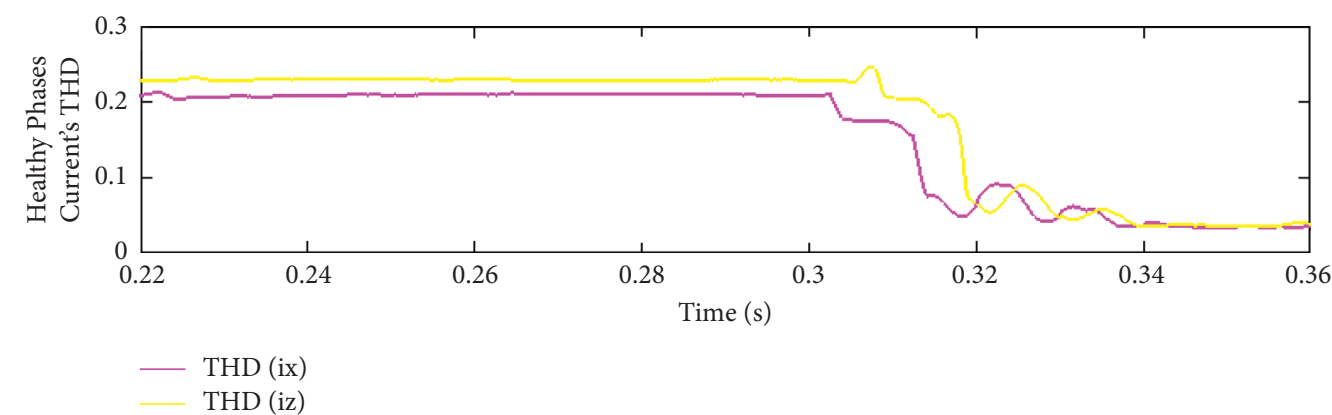

Figure 18: Simulation result of the THD of phases $\mathrm{X}$ and $\mathrm{Z}$, for multiple open-switch fault and fault-tolerant conditions.

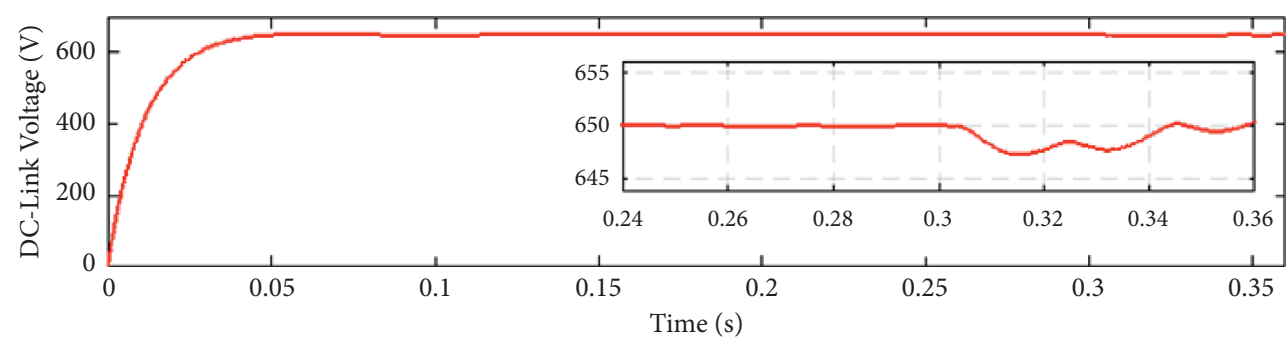

(a)

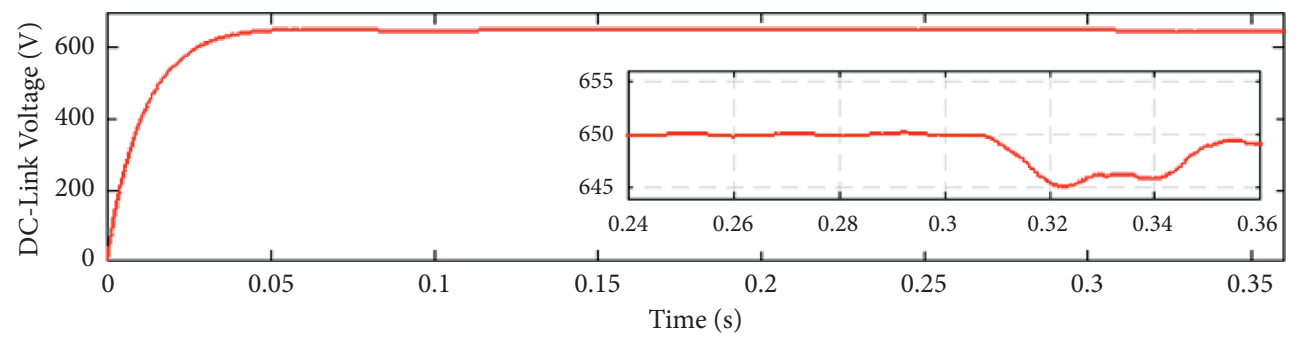

(b)

Figure 19: Continued. 


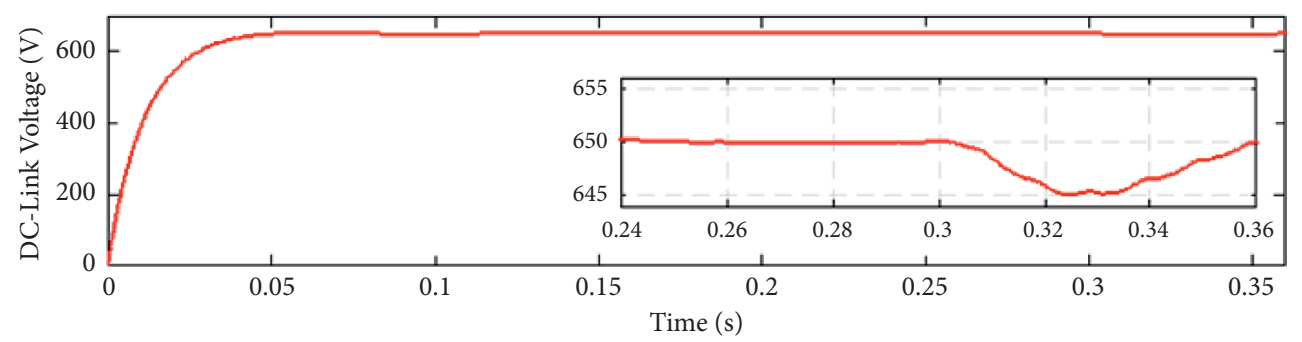

(c)

FIGURE 19: Simulation result of DC-link voltage ripple, for fault-tolerant conditions. (a) Single open-switch fault. (b) Multiple open-switch faults in different legs. (c) Multiple open-switch faults in one leg.

\section{Conclusion}

This paper proposes new fault diagnosis and fault-tolerant methods for the six-phase AC-DC converter for single and multiple open-switch faults. The introduced fault diagnosis approach has a simple process, which was integrated with the hysteresis controller, and requires neither complicated calculations, accurate modeling of the system, nor extra hardware. This method is robust against the load changes since a normalized indicator of the fault and an adaptive threshold are used. The main novelty of this research is tolerance against open-switch faults by changing the switching signals in the opposite phase of the faulty phase, without adding any equipment to the circuit. The proposed technique was able to reduce the overcurrent in the side phases, and the value of total harmonic distortion in these phases was also decreased. According to Table 5, in the worst case, at least $20 \%$ of the overcurrent value and $6 \%$ of the value of total harmonic distortion in side phase $(X)$ were reduced (multiple openswitch faults in $S_{1}$ and $S_{12}$ ). Moreover, the DC-link voltage is stabilized with an acceptable ripple, which is smaller than $1 \%$ of the reference value. The effectiveness of the proposed fault detection and fault-tolerant methods is confirmed by simulation results for a few different single and multiple fault cases. Evaluation of other switching techniques in the open-switch fault condition and implementation of modern controllers can be considered as future topics.

\section{Abbreviations}

GSC: $\quad$ Grid side converter

MSC: Machine side converter

PI: $\quad$ Proportional integral

PMSG: Permanent magnet synchronous generator

THD: Total harmonic distortion

TRIACs: Triode for alternating currents.

\section{Symbols}
$i$ : $\quad$ Current (A)
L: $\quad$ Inductance $(\mathrm{H})$
P: $\quad$ Power (w)
$R: \quad$ Resistance $(\Omega)$
T: Adaptive threshold
$u$ : Voltage (V)
$w_{1}$ : Angular frequency.

\section{Subscripts}

$d$, q: Direct and quadrature components

$f d$ : Fault detection

$m$ : Amplitude value

max: Maximum

min: Minimum

mod: Converter

ov: Overcurrent

ref: Reference

$s: \quad$ Source.

\section{Data Availability}

The MATLAB files data used to support the findings of this study are available from the corresponding author upon request.

\section{Conflicts of Interest}

The authors declare that they have no conflicts of interest.

\section{References}

[1] M. Shahbazi, P. Poure, and S. Saadate, "Real-time power switch fault diagnosis and fault-tolerant operation in a DFIGbased wind energy system," Renewable Energy, vol. 116, pp. 209-218, 2018.

[2] M. Nasiri, S. Mobayen, and Q. M. Zhu, "Super-twisting sliding mode control for gearless PMSG-based wind turbine," Complexity, vol. 2019, Article ID 6141607, 16 pages, 2019.

[3] C. N. Wang, W. C. Lin, and X. K. Le, "Modelling of a PMSG wind turbine with autonomous control," Mathematical Problems in Engineering, vol. 2014, Article ID 856173, 9 pages, 2014.

[4] A. Nahome Alemayehu, R. Zaimeddine, B. Liu, and T. Undeland, "Vector control of direct drive six phase permanent magnet synchronous generators," in Proceedings of the Conference of IEEE PES PowerTech, pp. 1-7, Milan, Italy, June 2011.

[5] W. Qiao and D. Lu, "A survey on wind turbine condition monitoring and fault diagnosis-Part I: components and subsystems," IEEE Transactions on Industrial Electronics, vol. 62, no. 10, pp. 6536-6545, 2015.

[6] C. Kaidis, B. Uzunoglu, and F. Amoiralis, "Wind turbine reliability estimation for different assemblies and failure severity categories," IET Renewable Power Generation, vol. 9, no. 8, pp. 892-899, 2015. 
[7] H. Guo, S. Guo, J. Xu, and X. Tian, "Power Switch opencircuit fault diagnosis of six-phase fault tolerant permanent magnet synchronous motor system under normal and faulttolerant operation conditions using the average current park's vector approach," IEEE Transactions on Power Electronics, vol. 36, no. 3, pp. 2641-2660, 2020.

[8] W.-S. Im, J.-M. Kim, D.-C. Lee, and K.-B. Lee, "Diagnosis and fault-tolerant control of three-phase AC-dc PWM converter systems," IEEE Transactions on Industry Applications, vol. 49, no. 4, pp. 1539-1547, 2013.

[9] F. Asghar, M. Talha, and S. H. Kim, "Neural network based fault detection and diagnosis system for three-phase inverter in variable speed drive with induction motor," Journal of Control Science and Engineering, vol. 2016, Article ID 1286318, 12 pages, 2016.

[10] I. Jlassi and A. J. M. Cardoso, "Fault-tolerant back-to-back converter for direct-drive PMSG wind turbines using direct torque and power control techniques," IEEE Transactions on Power Electronics, vol. 34, no. 11, pp. 11215-11227, 2019.

[11] H. Habibi, I. Howard, and S. Simani, "Reliability improvement of wind turbine power generation using model-based fault detection and fault tolerant control: a review," Renewable Energy, vol. 135, pp. 877-896, 2019.

[12] I. Jlassi, J. O. Estima, S. K. El Khil, N. M. Bellaaj, and A. J. M. Cardoso, "Multiple open-circuit faults diagnosis in back-to-back converters of PMSG drives for wind turbine systems," IEEE Transactions on Power Electronics, vol. 30, no. 5, pp. 2689-2702, 2014.

[13] Y. Mao, T. Peng, H. Han, S. Zhao, and Z. Li, “Open-circuited fault detection on switch of convertor in double-fed wind power generator set based on state observer," Computer Aided Engineering, vol. 24, no. 3, pp. 57-61, 2015.

[14] H. Yan, Y. Xu, F. Cai, H. Zhang, W. Zhao, and C. Gerada, "PWM-VSI fault diagnosis for a PMSM drive based on the fuzzy logic approach," IEEE Transactions on Power Electronics, vol. 34, no. 1, pp. 759-768, 2018.

[15] S. Karimi, A. Gaillard, P. Poure, and S. Saadate, "FPGA-based real-time power converter failure diagnosis for wind energy conversion systems," IEEE Transactions on Industrial Electronics, vol. 55, no. 12, pp. 4299-4308, 2008.

[16] H. Zhao and L. Cheng, "Open-switch fault-diagnostic method for back-to-back converters of a doubly fed wind power generation system," IEEE Transactions on Power Electronics, vol. 33, no. 4, pp. 3452-3461, 2017.

[17] A. M. Mendes and A. M. Cardoso, "Voltage source inverter fault diagnosis in variable speed AC drives, by the average current Park's vector approach," in Proceedings of the IEEE International Electric Machines and Drives Conference, pp. 704-706, Seattle, Was, USA, May 1999.

[18] A. M. S. Mendes, A. M. Cardoso, and E. S. Saraiva, "Voltage source inverter fault diagnosis in variable speed AC drives, by Park's vector approach," in Proceedings of the 1998 Seventh International Conference on Power Electronics and Variable Speed Drives, pp. 538-543, London, UK, September 1998.

[19] N. M. Freire, J. O. Estima, and A. M. Cardoso, "Converters fault-diagnosis in PMSG drives for wind turbine applications," in Proceedings of the IECON 2010-36th Annual Conference on IEEE Industrial Electronics Society, pp. 403-408, Glendale, ARI, USA, November 2010.

[20] N. M. Freire, J. O. Estima, and A. J. M. Cardoso, "Open-circuit fault diagnosis in PMSG drives for wind turbine applications," IEEE Transactions on Industrial Electronics, vol. 60, no. 9, pp. 3957-3967, 2012.
[21] S. Abramik, W. Sleszynski, J. Nieznanski, and H. Piquet, "A diagnostic method for on-line fault detection and localization in VSI-fed AC drives," in Proceedings of the 10th European Conference on Power Electronics and Applications, pp. 1-8, Toulouse, France, September 2003.

[22] S. Khomfoi, W. Sae-Kok, and I. Ngamroo, "An open circuit fault diagnostic technique in IGBTs for AC to DC converters applied in microgrid applications," Journal of Power Electronics, vol. 11, no. 6, pp. 801-810, 2011.

[23] J. O. Estima and A. J. Marques Cardoso, "A new approach for real-time multiple open-circuit fault diagnosis in voltagesource inverters," IEEE Transactions on Industry Applications, vol. 47, no. 6, pp. 2487-2494, 2011.

[24] I. Jlassi and A. J. M. Cardoso, "IGBTs and current sensors fault diagnosis in direct-drive PSMG wind turbine systems using adaptive thresholds," in Proceedings of the IECON 2017-43rd Annual Conference of the IEEE Industrial Electronics Society, pp. 5072-5077, Beijing, China, August 2017.

[25] I. Jlassi, J. O. Estima, S. K. El Khil, N. M. Bellaaj, and A. J. M. Cardoso, "A robust observer-based method for IGBTs and current sensors fault diagnosis in voltage-source inverters of PMSM drives," IEEE Transactions on Industry Applications, vol. 53, no. 3, pp. 2894-2905, 2016.

[26] P. Duan, K. G. Xie, L. Zhang, and X. Rong, "Open-switch fault diagnosis and system reconfiguration of doubly fed wind power converter used in a microgrid," IEEE Transactions on Power Electronics, vol. 26, no. 3, pp. 816-821, 2010.

[27] A. Mohamed, S. Vanteddu, and O. Mohammed, "Protection of bi-directional AC-DC/DC-AC converter in hybrid AC/DC microgrids," in Proceedings of the 2012 Proceedings of IEEE Southeastcon, pp. 1-6, Orlando, FL, USA, March 2012.

[28] M. O. Aboelhassan, T. Raminosoa, A. Goodman, L. De Lillo, and C. Gerada, "Performance evaluation of a vector-control fault-tolerant flux-switching motor drive," IEEE Transactions on Industrial Electronics, vol. 60, no. 8, pp. 2997-3006, 2012.

[29] Y. Hu, L. Zhang, W. Huang, and F. Bu, "a fault-tolerant induction generator system based on instantaneous torque control (ITC)," IEEE Transactions on Energy Conversion, vol. 25, no. 2, pp. 412-421, 2010.

[30] B. A. Welchko, T. A. Lipo, T. M. Jahns, and S. E. Schulz, "Fault tolerant three-phase AC motor drive topologies: a comparison of features, cost, and limitations," IEEE Transactions on Power Electronics, vol. 19, no. 4, pp. 1108-1116, 2004.

[31] R. L. de Araujo Ribeiro, C. B. Jacobina, E. R. C. Da Silva, and A. M. N. Lima, "Fault-tolerant voltage-fed PWM inverter AC motor drive systems," IEEE Transactions on Industrial Electronics, vol. 51, no. 2, pp. 439-446, 2004.

[32] N. M. Freire and A. J. M. Cardoso, "A fault-tolerant PMSG drive for wind turbine applications with minimal increase of the hardware requirements," IEEE Transactions on Industry Applications, vol. 50, no. 3, pp. 2039-2049, 2013.

[33] N. M. Freire and A. J. M. Cardoso, "Fault-tolerant PMSG drive with reduced DC-link ratings for wind turbine applications," IEEE Journal of Emerging and Selected Topics in Power Electronics, vol. 2, no. 1, pp. 26-34, 2013.

[34] W. S. Im, J. J. Moon, J. M. Kim, D. C. Lee, and K. B. Lee, "Fault tolerant control strategy of 3-phase AC-DC PWM converter under multiple open-switch faults conditions," in Proceedings of the 2012 Twenty-Seventh Annual IEEE Applied Power Electronics Conference and Exposition (APEC), pp. 789-795, Orlando, FL, USA, February 2012.

[35] R. Bolbolnia, E. Heydari, and K. Abbaszadeh, "Fault tolerant control in direct-drive PMSG wind turbine systems under open-circuit faults," in Proceedings of the 2020 11th Power 
Electronics, Drive Systems, and Technologies Conference (PEDSTC), pp. 1-5, Iran, February 2020.

[36] K. Zhou, D. Wang, Y. Yang, and F. Blaabjerg, Periodic Control of Power Electronic Converters, Institution of Engineering and Technology, London, UK, 2016.

[37] J. Han, X. Zhou, S. Lu, and P. Zhao, "A three-phase bidirectional grid-connected AC/DC converter for V2G applications," Journal of Control Science and Engineering, vol. 2020, Article ID 8844073, 12 pages, 2020.

[38] S. Khojet El Khil, I. Jlassi, A. J. Marques Cardoso, J. O. Estima, and N. Mrabet-Bellaaj, "Diagnosis of open-switch and current sensor faults in PMSM drives through stator current analysis," IEEE Transactions on Industry Applications, vol. 55, no. 6, pp. 5925-5937, 2019. 